\title{
Prevalence of Cryptosporidium species oocysts among small ruminants in Potiskum livestock market, Yobe State, Nigeria
}

\author{
Abare, M. S. ${ }^{1 *}$, Maikai, B. V. ${ }^{1}$ and Okubanjo, $0.0^{2}$ \\ 1Department of Veterinary Public Health and Preventive Medicine, Faculty of Veterinary Medicine, Ahmadu Bello \\ University Zaria, Kaduna State, Nigeria. \\ ${ }^{2}$ Department of Veterinary Parasitology and Entomology, Faculty of Veterinary Medicine, Ahmadu Bello University Zaria, \\ Kaduna State, Nigeria. \\ ${ }^{*}$ Corresponding authors: Email: musasabare@gmail.com; Tel: +2347066338333.
}

Copyright @ 2019 Abare et al. This article remains permanently open access under the terms of the Creative Commons Attribution License 4.0, which permits unrestricted use, distribution, and reproduction in any medium, provided the original work is properly cited.

Received 13th November, 2018; Accepted 9th January, 2019

ABSTRACT: A cross-sectional study was carried out to determine the prevalence of Cryptosporidium species oocysts in small ruminants in Potiskum livestock market, Yobe State, Nigeria. Faecal samples from 203 animals; 100 sheep and 103 goats were tested using modified Ziehl-Neelsen staining technique. An overall prevalence of $20.7 \%(42 / 203)$ was recorded in the study with a higher prevalence of $21.4 \%(22 / 103)$ in goats than in sheep $20 \%(20 / 100)$; although the difference was not significant $(\mathrm{p}>0.05)$. In goats, the rate of Cryptosporidium species oocyst was higher in male (27.8\%) than in female $(22.4 \%)$, in young (30.6\%) than in adults $(22.4 \%)$, in those with loose/watery faeces $(45.5 \%)$ than those with well-formed faeces $(22.8 \%)$ but the differences were not significant $(p>0.05)$. In sheep, the rate of infection was higher in female $(16.9 \%)$ than in male $(13.0 \%)$, in young $((19.2 \%)$ than in adults $(14.9 \%)$ but the differences were not significant $(p>0.05)$. The prevalence was significantly $(p=0.010)$ higher in sheep with loose/watery faeces $(45.5 \%)$ than in those with wellformed faeces $(12.4 \%)$. Breed of sheep did not significantly $(p>0.05)$ influence the prevalence rates, although the Uda breed had higher prevalence (25\%) than the Balami (14.3\%) and Yankasa (12.7\%) breeds. A similar trend was observed for the sahelian breed of goats (35.7\%) compared to the Red sokoto (23.7\%), West African dwarf (16.7\%) and mixed breeds $(10.0 \%)(p=0.367)$. Animals brought to the livestock market from Ngalda town showed highest prevalence of $36.4 \%$ than those from the other areas with prevalence rates of (0 to 33.3\%). The finding of Cryptosporidium species oocysts in $20.7 \%$ of small ruminants in this study underscores the role of this zoonotic parasite diseases in animals and man and loose/watery faeces is a significant factor in the spread among small ruminants.

Keywords: Sheep, goats, market, modified Ziehl-Neelsen, prevalence, Potiskum.

\section{INTRODUCTION}

Cryptosporidium is a zoonotic protozoan parasite that causes cryptosporidiosis, an enteric infection in a wide variety of mammals including humans, cattle, sheep, goat, pig and horses worldwide (Quilez et al., 2008; Nasir et al., 2009). Clinically, the disease is characterized by anorexia and diarrhea, which may result in poor growth rate (Taylor et al., 2007). Infection with Cryptosporidium in young sheep and goats may lead to morbidity and even mortality due to diarrhea (Thompson et al., 2005). Cryptosporidium species infecting sheep and goats have been found to be of public health significance (Robertson et al., 2010; Wang et al., 2014). Oocysts are discharged in the faeces of infected ruminants and are of primary importance for the dispersal and survival of the parasites (Bowman, 2003).

The oocysts are a source of infection for animals and humans (Singla et al., 2013) and transmission occurs by 
faeco oral route (OIE, 2016). In humans, infection with Cryptosporidium causes diarrheal disease (Checkley et al., 2015), and chronic and fatal disease in immunocompromised individuals (Wilhelm and Yarovinsky, 2014). Additionally, Cryptosporidium infection has been linked to cancer in humans (Lendner et al., 2011; Benamrouz et al., 2012).

For effective disease prevention, an understanding of the environmental factors that predispose animals and man to infectious causes of diarrhea like Cryptosporidium species is required (Rossle and Latif, 2013; Collinet-Adler et al., 2015). Although several studies aimed at detecting and identifying Cryptosporidium species in ruminants have been conducted in Nigeria (Kwaga et al., 1988; Maikai et al., 2011; Pam et al., 2013; Akinkuotu and Fagbemi, 2014; Danladi and Ugbomoiko, 2015), the knowledge of parasite occurrence and worldwide distribution in animals is still not complete (Xiao, 2010).

Potiskum livestock market is one of the largest livestock markets in West Africa and small ruminants from other parts of the state are brought to the market for sale (Ramsar, 2008). These animals are kept in the market until they are sold and then transported to other parts of the country. This practice poses a potential risk of transmission of parasite like Cryptosporidium species between animals as well as to humans.

Thus, the aim of the study was to determine the prevalence of Cryptosporidium species oocysts among small ruminants in Potiskum livestock market, Yobe State, Nigeria.

\section{MATERIALS AND METHODS}

\section{Study area and study design}

The study area was Potiskum Local Government Areas of Yobe State, Nigeria (Figure 1). It is located between longitude $11^{\circ} 43^{\prime} \mathrm{N}$ and latitude $11^{\circ} 04^{\prime} \mathrm{E}$. Potiskum livestock market is the largest livestock market in the state and serves as the main market where animals are loaded in trucks and transported to other parts of the country. The mean temperature in Potiskum is about $37^{\circ} \mathrm{C}$. The highest temperature of $42^{\circ} \mathrm{C}$ is normally experienced in April, while minimum temperature (about $30^{\circ} \mathrm{C}$ ) are normally recorded in December (lloeje, 1977). About $713 \mathrm{~mm}$ precipitation falls annually. The profile of the soil is poorly developed and it has a low water retention capacity (Price et al., 1990). Potiskum have an average relative humidity of 39.5\% (Eludoyin et al., 2014).

\section{Sampling}

A total of 203 faecal samples were randomly collected from sheep and goats in the livestock market, 100 from sheep and 103 from goats of different ages. Convenience sampling technique was employed to select the animals, which was based on the availability of the animals and the willingness of the owners to participate in the study. Age of the animals was determined using their dentition. Sheep and goats between the age range of six (6) months and below were considered to be young, while those up to 7 months and above were considered as adults (Dagnachew et al., 2011). Sampling was done between October and December 2016. Fresh faecal samples were collected from the rectum of each animal using a disposable hand gloves and emptied into a sterile, airtight, plastic tube. Samples were stored in $10 \%$ formaldehyde and were transported in icebox to the Parasitic Zoonoses Laboratory of the Department of Veterinary Public Health and Preventive Medicine, Ahmadu Bello University, Zaria for analysis. General information on the animal was recorded which includes species, age, sex, breed, source of animal and faecal consistency. Faeces were observed for either being well formed or loose/watery.

\section{Sample processing and laboratory procedures using Formol-Ether concentration and modified Ziehl- Neelsen Staining (mZN) technique}

The modified Ziehl-Neelsen technique was performed as described by WHO (1991). Briefly, $1 \mathrm{gm}$ of faeces was mixed in $10 \mathrm{ml}$ of $10 \%$ formaldehyde in a universal bottle using an applicator stick. The homogenized faeces was sieved into a centrifuge tube using a funnel and gauze to which $3 \mathrm{ml}$ of diethyl ether was added. The centrifuge tubes were corked and shaken gently to mix properly. The tube was centrifuged at $2000 \mathrm{rpm}$ for 2 minutes and the supernatant decanted. The sediment was mixed with a spatula from which a thin smear was made on a clean glass slide. After air-drying, the smear was fixed in methanol for 2 to $3 \mathrm{~min}$. The slide was flooded with cold carbolfuschin for 5 to $10 \mathrm{~min}$ and then with $1 \%$ hydrochloric-acid ethanol until colour ceases to flow out and rinsed in tap water. It was then counterstained with $0.25 \%$ methylene blue for 30 seconds, rinsed in tap water again and air-dried. The slide was then examined under the compound microscope at $x 10$ and $x 40$ objectives. The appearance of a bright rose-pink spherules on a bluish green background indicate the presence of Cryptosporidial oocysts

\section{Data analyses}

Statistical Package for Social Sciences (SPSS, version 20.0) (SPSS Inc. Chicago IL, USA) was used to analyze the data obtained. Chi-square, odds ratio and 95\% confidence was used to test the association between prevalence of Cryptosporidium species oocysts and 


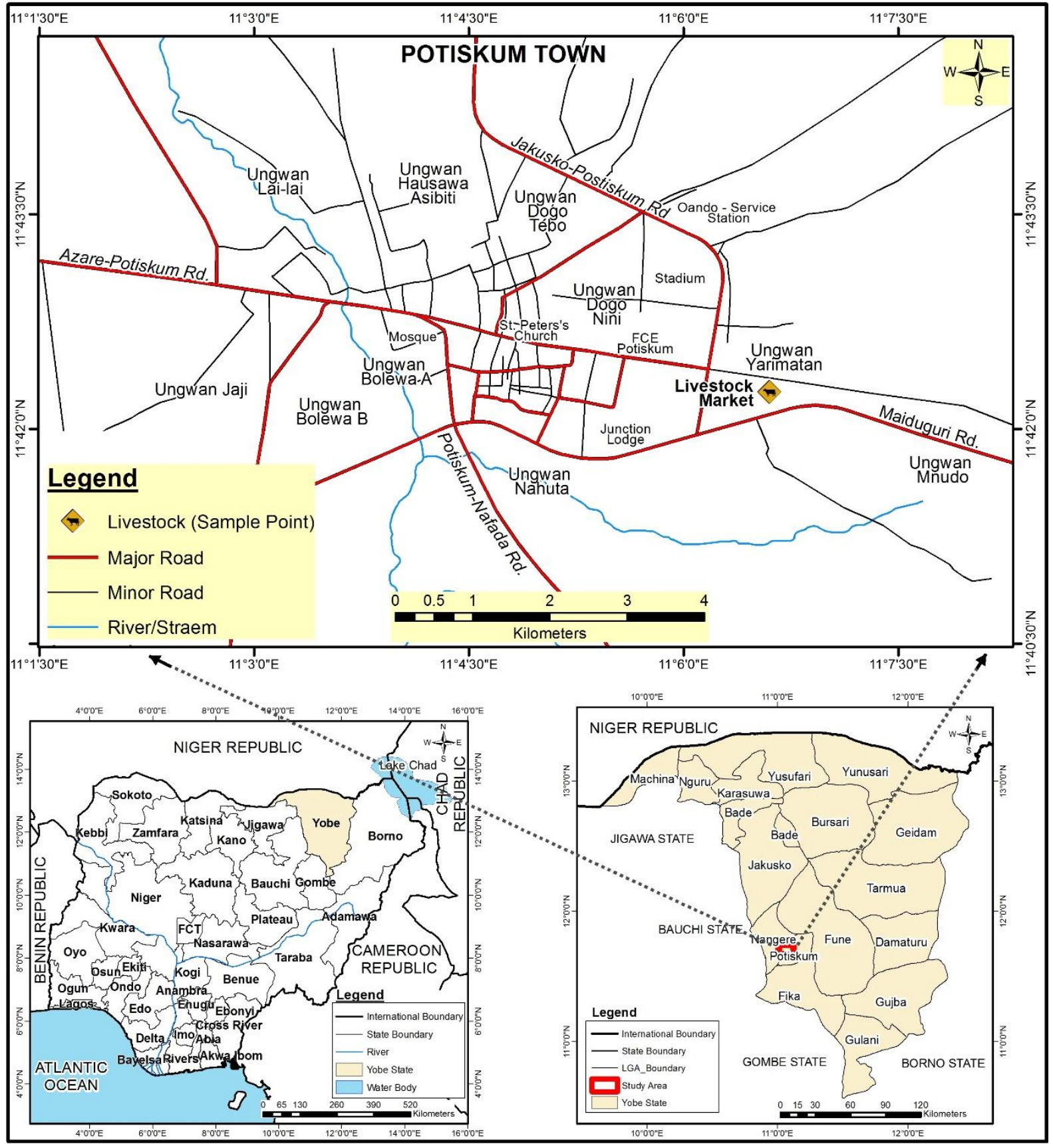

Figure 1. Map of Potiskum Town showing Sampling Points. Modified from the Street Map of Potiskum Town.

species, age, sex, breed, source of animal and faecal consistency of the animals studied. Results were presented in tables. Values of $P \leq 0.05$ were considered statistically significant.

\section{RESULTS}

Cryptosporidium species oocysts were detected in the small ruminants examined. A total of $42(20.7 \%)$ of the animals were positive for Cryptosporidium species oocysts. The rate of infection was higher in goats $(21.4 \%)$ than in sheep $(20.0 \%)$, but the difference was not significant $(p>0.05)$ (Table 1).

Table 2 depicts prevalence with respect to infection in goats. Although infection in male goats was relatively higher than in females, the rates were statistically comparable $(p>0.05)$. Young goats tended to be more infected than the adult ones, However, the distribution was 
Table 1. Prevalence of Cryptosporidium spp. oocysts and species small ruminants in Potiskum, Yobe State, Nigeria.

\begin{tabular}{lccccc}
\hline Species & No. Samples examined & Positive samples & Specific rate (\%) & Odds ratio & 95\% Cl on OR \\
\hline Sheep & 100 & 20 & 20.0 & 0.920 & \multirow{2}{*}{$0.466-1.817$} \\
Goats ${ }^{\text {ref }}$ & 103 & 22 & 21.4 & & \\
Total & 203 & 42 & 20.7 & & \\
\hline
\end{tabular}

Reference standards (ref).

Table 2. Prevalence of Cryptosporidium spp. oocysts and consistency of faeces, sex and age of goats in Potiskum livestock market.

\begin{tabular}{lcccccc}
\hline Factors & $\begin{array}{c}\text { No. Samples } \\
\text { examined }\end{array}$ & $\begin{array}{c}\text { Positive } \\
\text { samples }\end{array}$ & $\begin{array}{c}\text { Specific rate } \\
(\%)\end{array}$ & $\begin{array}{c}\text { Odds } \\
\text { ratio }\end{array}$ & 95\% Cl on OR & P- value \\
\hline Sex & 54 & 15 & 27.8 & & & \\
Male & 49 & 11 & 22.4 & 1.329 & $0.542-3.259$ & 0.535 \\
Female ref & & & & & & \\
Age (months) & 36 & 11 & 30.6 & 0.656 & $0.263-1.633$ & 0.365 \\
$\begin{array}{l}\text { Young } \\
\text { Adults ref }\end{array}$ & 67 & 15 & 22.4 & & & \\
& & & & & & \\
Faecal consistency & & & & & & \\
Well formed & 92 & 21 & 22.8 & 2.817 & $0.781-10.162$ & \\
Loose/watery ref & 11 & 5 & 45.5 & & & \\
\hline
\end{tabular}

Reference standards (ref), $\mathrm{Cl}$ - Confidence Interval, OR - Odds Ratio.

Table 3. Prevalence of Cryptosporidium spp. oocysts and consistency of faeces, sex and age of sheep in Potiskum livestock market.

\begin{tabular}{|c|c|c|c|c|c|c|}
\hline Factors & $\begin{array}{l}\text { No. Samples } \\
\text { examined }\end{array}$ & $\begin{array}{l}\text { Positive } \\
\text { samples }\end{array}$ & $\begin{array}{c}\text { Specific rate } \\
(\%)\end{array}$ & $\begin{array}{l}\text { Odds } \\
\text { ratio }\end{array}$ & $95 \% \mathrm{Cl}$ on OR & P-value \\
\hline \multicolumn{7}{|l|}{ Sex } \\
\hline Male & 23 & 3 & 13.0 & \multirow{2}{*}{0.738} & \multirow{2}{*}{$0.191-2.854$} & \multirow[t]{2}{*}{0.660} \\
\hline Female ${ }^{\text {ref }}$ & 77 & 13 & 16.9 & & & \\
\hline \multicolumn{7}{|l|}{ Age (months) } \\
\hline Young & 26 & 5 & 19.2 & \multirow{2}{*}{0.733} & \multirow{2}{*}{$0.228-2.355$} & \multirow[t]{2}{*}{0.602} \\
\hline Adults ${ }^{\text {ref }}$ & 74 & 11 & 14.9 & & & \\
\hline \multicolumn{7}{|c|}{ Faecal consistency } \\
\hline Well formed & 89 & 11 & 12.4 & \multirow{2}{*}{5.909} & \multirow{2}{*}{$1.541-22.663$} & \multirow[t]{2}{*}{$0.010^{*}$} \\
\hline Loose/watery ref & 11 & 5 & 45.5 & & & \\
\hline
\end{tabular}

Reference standards (ref), $\mathrm{Cl}$ - Confidence Interval, OR - Odds Ratio, ${ }^{*} \mathrm{p}<0.05$ is significant.

not significant $(p>0.05)$. Goats with loose/watery faeces were 2.817 times prone to infection than those with wellformed faeces, but distribution was not statistically significant $(p=0.114)$.

The distribution of oocysts in sheep is summarized in Table 3. The occurrence of the oocysts was common in female $(16.9 \%)$ sheep than male (13.0\%), although the distribution was not sex related ( $p>0.05)$. Young $(19.2 \%)$ sheep are slightly more infected than the adult (14.9\%), but was not statistically significant $(p>0.05)$. Sheep with loose/watery faeces shedded significantly $(p<0.05)$ higher percentage of oocysts $(45.5 \%)$ and were more than five 
Table 4. Occurrence of Cryptosporidium spp. oocysts according to the breed of small ruminants in Potiskum livestock market.

\begin{tabular}{lcccccc}
\hline Breed & No. examine & No. positive & Specific rate (\%) & df & $\mathbf{X}^{\mathbf{2}}$ & $\mathbf{P}$ - value \\
\hline Sheep Breed & & & & & & \\
Yankasa & 55 & 7 & 12.7 & & & 0.381 \\
Balami & 21 & 3 & 14.3 & 2 & & \\
Uda & 24 & 6 & & & & \\
Goat breed & & & 35.7 & & & \\
Sahelian & 28 & 10 & 23.7 & 3 & 3.164 & 0.367 \\
Red Sokoto & 59 & 14 & 16.7 & & & \\
WAD & 6 & 1 & 10.0 & & & \\
Mixed breed & 10 & 1 & & & & \\
\hline
\end{tabular}

WAD - West African dwarf, Df - Degree of freedom, $\mathbf{X}^{2}-$ Chi-square.

Table 5. Association between the source of animal and the occurrence of Cryptosporidium spp. Oocysts.

\begin{tabular}{|c|c|c|c|c|c|c|}
\hline Source & Number examined & Number positives & Specific rate (\%) & $x^{2}$ & df & P-value \\
\hline Potiskum town & 37 & 8 & 21.6 & \multirow{10}{*}{4.011} & \multirow{10}{*}{8} & \multirow{10}{*}{0.856} \\
\hline Ngelzarma & 39 & 8 & 20.5 & & & \\
\hline Ngalda & 11 & 4 & 36.4 & & & \\
\hline Babban gida & 23 & 4 & 17.4 & & & \\
\hline Damaturu & 42 & 9 & 21.4 & & & \\
\hline Buni yadi & 22 & 5 & 22.7 & & & \\
\hline Garga & 5 & 0 & 0.0 & & & \\
\hline Gadaka & 21 & 3 & 14.3 & & & \\
\hline Garin buba & 3 & 1 & 33.3 & & & \\
\hline Total & 203 & 42 & 21 & & & \\
\hline
\end{tabular}

$\mathrm{df}-$ Degree of freedom, $\mathbf{x}^{2}-$ Chi-square.

times likely to be infected than those with well-formed faeces (12.4\%).

The rate of infection was higher in Uda (25.0\%) breed of sheep, followed by balami (14.3\%), and Yankasa (12.7\%), but the difference was not significant $(p>0.05)$. Similarly, in breed of goats, the rate of infection was higher in Sahelian (35.7\%), followed by Red Sokoto (23.7\%), West African dwarf (16.7\%) and the least was mixed breed $(10.0 \%)$, but the difference was not significant $(p>0.05)$ (Table 4).

Table 5 shows the association between the prevalence of Cryptosporidium species oocysts in small ruminants and source of the animal in the livestock market. Small ruminants that were brought to livestock market from Ngalda had the highest infection rate of $36.4 \%$, followed by Garin buba (33.3\%), Buni yadi (22.7\%), Potiskum (21.6\%), Damaturu (21.4\%), Ngelzarma (20.5\%), Babban gida (17.4\%) and Gadaka (15.0\%). No oocyst was recorded in small ruminants from Garga $(0 \%)$. but the difference was not significant $(p>0.05)$.

\section{DISCUSSION}

The 20\% prevalence of Cryptosporidium species oocysts in sheep in this study is similar to the report of Regassa et al. (2013) who recorded $22.2 \%$ in sheep in Ethiopia. However, it is higher as compared to the $11.7 \%$ reported by Danladi and Ugbomoiko, (2015) and $16.0 \%$ by Pam et al. (2013) in Nigeria. This indicates that cryptosporidiosis is a global problem affecting a wide range of farm animals. Similarly, the $21.4 \%$ prevalence in goats is consistent with the report of Pam et al., 2013, but lower than $72.5 \%$ recorded in Veracruz, Mexico (Romero-salas et al., 2016). The prevalence recorded in this study implies that animals in livestock market in Potiskum may serve as reservoirs of infection to other animals and humans in other parts of the country where these animals are been transported to.

A slightly higher rate of detection in male goats than female was observed which is similar to previous reports in goats and other animal species (Maikai et al., 2009; Akinkuotu and Fagbemi, 2014; Danladi and Ugbomoiko, 
2015). On the contrary, female sheep were more infected than male as observed by Danladi and Ugbomoiko, (2015). The reason for this observation is not known. Further research is required to elucidate this and other possible reasons for the differences in infection rates between the sexes (Akinkuotu et al., 2014). Previous works have indicated that cryptosporidiosis is significantly associated with young than adult animals (Geurden et al., 2006; Yang et al., 2009; Zhang et al., 2013). But on the contrary, distribution of infection between young and adult animals in this study was not age related $(P>0.05)$ suggesting a possible interplay of other exposure risks. This was also observed by Ayinmode and Fagbemi (2010).

The higher rate of Cryptosporidium infection in sheep with loose/watery faeces recorded in this study, is in line with the reports of Maurya et al. (2013), Caccio et al. (2013) and Danladi and Ugbomoiko (2015) who inferred the presence of diarrhoea in young animals as a significant source of oocyst contamination of the environment. Other factors such as the environment, management practices, genetics and immune status of the animals might have contributed to such outcome.

It has been shown that the breed of small ruminants has no significant influence on the prevalence of Cryptosporidium oocysts (Regassa et al., 2013; Kaupke et al., 2017), which is consistent with the findings in this study.

Nine areas were identified as the major sources of these sheep and goats in Potiskum livestock market with small ruminants from Ngalda having the highest prevalence $36.4 \%$. Ngalda is located in Fika Local Government area of Yobe State and it is one of the areas with a very large body of water which encourages several agricultural activities. Sheep and goats in the area are usually seen along the river banks grazing. Wetness and high humidity along the river bank can encourage oocyst survival and increase their viability when present. This may be the reason why small ruminants from Ngalda had the highest rate of occurrence of Cryptosporidium oocysts. This report is similar to that of Faleke et al. (2014).

\section{Conclusion}

Prevalence of Cryptosporidium species oocysts among sheep and goats in Potiskum livestock market is relatively high. Infection was widely distributed among small ruminants regardless of their species, age, sex, or breed. The study also highlights the significance of loose/watery faeces as a key factor in the spread of infection. Efforts should be directed towards improving quarantine systems, especially in livestock markets, in order to ensure healthy production of ruminants and reduce possible zoonotic transmission of the parasite in Nigeria.

\section{CONFLICT OF INTEREST}

The authors declare that they have no conflict of interest.

\section{REFERENCES}

Akinkuotu, O. A., \& Fagbemi, B. O. (2014). Occurrence of Cryptosporidium species Coproantigens on a University teaching farm in Nigeria. Sokoto Journal of Veterinary Science, 12 (12), 41-46.

Akinkuotu, O. A., Fagbemi, B. O., Otesile, E. B., Dipeolu, M. A. \& Ayinmode, A. B. (2014). Cryptosporidium infection in cattle in Ogun state, Nigeria. Sokoto Journal of Veterinary Science, 12 (2), 52-56

Ayinmode, A. B., \& B. O. Fagbemi, (2010). Prevalence of Cryptosporidium infection in cattle from South Western Nigeria. Veterinaski Arhiv Journal, 80(6), 723-731

Benamrouz, S., Conseil, V., Creusy, C., Calderon, E., Dei-Cas, E., \& Certad, G. (2012). Parasites and malignancies, a review, with emphasis on digestive cancer induced by Cryptosporidium parvum (Alveolata: Apicomplexa). Parasite: journal de la Société Française de Parasitologie, 19(2), 101115.

Bowman, D. D. (2003). Georgis' Parasitology for Veterinarians, Saunders. 8th ed. Pp. 98.

Caccio`, S. M., Sannella, A. R., Mariano, V., Valentini, S., Berti, F., Tosini, F., Pozio, E. (2013). A rare Cryptosporidium parvum genotype associated with infection of lambs and zoonotic transmission in Italy. Veterinary Parasitology, 191(1-2), 128131.

Checkley, W., White, A. C. Jr., Jaganath, D., Arrowood, M. J., Chalmers, R. M., Chen, X. M., (2015). A review of the global burden, novel diagnostics, therapeutics, and vaccine targets for Cryptosporidium. Lancet Infectious Diseases, 15(1), 85-94.

Collinet-Adler, S., Babji, S., Francis, M., Kattula, D., Premkumar, P. S., Sarkar, R. (2015). Environmental factors associated with high fly densities and diarrhea in Vellore, India. Applied and Environmental Microbiology, 81(17), 6053-6058.

Dagnachew, S., Amamute, A., \& Temesge, W. (2011). Epidemiology of gastrointestinal helminthiasis of small ruminants in selected sites of North Gondar zone, Northwest Ethiopia. Ethiopian Veterinary Journal, 15(2), 57-68

Danladi, Y.K., \& Ugbomoiko, U. S. (2015). Epidemiology of Cryptosporodiosis in Ruminant Species in Kebbi State, Nigeria. IOSR Journal of Agriculture and Veterinary Science, 8(12), 39-44.

Eludoyin, O. M., Adelekan, I. O., Webster, R., \& Eludoyin, A. O. (2014). Air temperature, relaive humidity, climate regionalization and thermal comfort of Nigeria. International Journal of climatology, 34, 2000-2018

Faleke, O. O., Yabo, Y. A., Olaleye, A. O., Dabai, Y. U., \& Ibitoye, E. B. (2014). Point Prevalence of Cryptosporidium Oocyst in Calves Grazing along River Rima Bank in Sokoto, Nigeria. Pakistan Journal of Biological Sciences, 17(3), 443-446.

Geurden, T., Goma, F. Y., Siwila, J., Phiri, I. G. K., Mwanza, A. M., Gabriel, S., Claerebout, E., \& Vercruysse, J. (2006). Prevalence and genotyping of Cryptosporidium in three cattle husbandry systems in Zambia. Veterinary Parasitology, 138(34), 217-222.

lloeje, N. P (1977). A geography of Nigeria: Longman Itd

Kaupke, A., Michalski, M. M., \& Rzezutka, A. (2017). Diversity of Cryptosporidium species occurring in sheep and goat breeds reared in Poland. Parasitology Research, 116(3), 871-879.

Kwaga, J. K., Umoh, J. U., Odoba, M. B (1988). Cryptosporidium infection in humans with gastroenteritis in Zaria, Nigeria. Epidemiology and Infection, 101(1), 93-97. 
Lendner, M., Etzold, M., \& Daugschies, A. (2011). Cryptosporidiosis--an update. Berliner und Munchener tierarztliche Wochenschrift, 124(11-12), 473-484.

Maikai, B. V., Umoh, J. U., Kwaga, J. K. P., Maikai, V. A., \& Egege, S. C. (2009). Prevalence and risk factors associated with faecal shedding of Cryptosporidium oocysts in piglets, Kaduna, Nigeria. Journal of Parasitology Vector Biology, 1(1), 1-4.

Maikai, B. V., Umoh, J. U., Kwaga, J. K., Lawal, I. A., Maikai, V. A., Cama, V., \& Xioa, L. (2011). Molecular Characterisation of Cryptosporidium spp. in native breeds of cattle in Kaduna State, Nigeria. Veterinary Parasitology, 178(3-4), 241-245.

Maurya, P. S., Rakesh, R. L., Pradeep, B., Kumar, S., Kundu, K., Garg, R, Garg R., Ram H., Kumar, A., \& Banerjee, P. S. (2013). Prevalence and risk factors associated with Cryptosporidium spp. infection in young domestic livestock in India. Tropical Animal Health and Production, 45(4), 941-946.

Nasir, A., Avais, M., Khan, M. S., \& Ahmad, N. (2009). Prevalence of Cryptosporidium parvum infection in Lahore (Pakistan) and its association with diarrhea in dairy calves. International Journal of Agriculture and Biology, 11(2), 221224.

Office International des Epizootics (OIE) (2016). Terrestrial Manual chapter 2.9.4. Cryptosporidiosis. PP 1 - 15. Adopted version by World Health Assemble Delegates

Pam, V. A., Dakul, D. A., Karshima, N. S., Bata S.I., Ogbu, K. I., Danie, L. N., \& Hassan, A. A. (2013). Survey of Cryptosporidium species among ruminants in Jos, Plateau State, North-Central Nigeria. Journal of Veterinary Advances, 3(2), 49-54.

Price, S. D., Justice, C. O., \& Los, S. O. (1990). Remote sensing of the sahelian environment. A review of the current studies and future prospects. Technical center for agriculture and cooperation.

Quilez, J., Torres, E., Chalmers, R. M., Hadfield, S. J., Cacho, E., \& Sa'nchez-Acedo, C. (2008). Cryptosporidium Genotypes and Subtypes in Lambs and Goat Kids in Spain. Applied and Environmental Microbiology, 74(19), 6026-6031.

Ramsar (2008). Nigeria's new wetlands of international importance. Ramsar convention secretariat, Rue Mauverney28, CH-1196 Gland, Switzerland. Retrieved on 19 June, 2017

Regassa, A., Gizaw, O., Abunna, F., Abebe, R., Beyene, D., Megersa, B., Debela, E., Asmare. K., \& Skierve, E. (2013). Cryptosporidium in Calves, Lambs and Kids at Haramaya, eastern. Ethiopian Veterinary Journal, 17(1), 81-94.

Robertson, L. J., Gjerde, B. K., Furuseth, H. E. (2010). The zoonotic potential of Giardia and Cryptosporidium in Norwegian sheep: a longitudinal investigation of 6 flocks of lambs. Veterinary Parasitology, 171(1-2), 140-145.
Romero-Salas, D., Alvarado-Esquivel, C., Cruz-romero, A., Aguilar-Domínguez, M., Ibarra-Priego, N., Merino-charrez, J. O., Pérez, D. E., León, A. A., \& Hernández-tinoco, J. (2016). Prevalence of Cryptosporidium in small ruminants from Veracruz, Mexico. BioMed Central Veterinary Research, 12(1), 14.

Rossle, N. F., \& Latif, B. (2013). Cryptosporidiosis as threatening health problem: a review. Asian Pacific Journal of Tropical Biomedicine, 3, 916-924.

Singla, L. D., Gupta, M. P., Singh, H., Singh, S. T., Kaur, P., \& Juyal, P. D. (2013). Antigen based diagnosis of Cryptosporidium parvum infection in faeces of cattle and buffalo calves. Indian Journal of Animal Science, 83(1), 37-39.

Taylor, M. A., Coop, R. L., \& Wall, R. L. (2007). Veterinary Parasitology. Blackwell Publishing, USA, 3rd edn. Pp. 103115.

Thompson, R. C., Olson, M.E., Zhu, G., Enomoto, S., Abrahamsen, M.S., Hijjawi, N.S. (2005). Cryptosporidium and Cryptosporidiosis. Advances in Parasitology, 59, 77-158.

Wang, R., Li, G., Cui, B., Huang, J., Cui, Z., Zhang, S. (2014). Prevalence, molecular characterization and zoonotic potential of Cryptosporidium spp. in goats in Henan and Chongqing, China. Experimental Parasitology, 142, 11-16.

Wilhelm, C. L., \& Yarovinsky, F. (2014). Apicomplexan infections in the gut. Parasite Immunology, 36, 409-420.

World Health Organization, (1991). Basic laboratory methods in medical parasitology. World Health Organization, Geneva. p. 16.

Xiao, L. (2010). Molecular epidemiology of cryptosporidiosis: an update. Experimental Parasitology, 124(1), 80-89.

Yang, R., Jacobson, C., Gordon, C., \& Ryan, U., (2009). Prevalence and molecular characterisation of Cryptosporidium and Giardia species in pre-weaned sheep in Australia. Veterinary Parasitology, 161(1-2), 19-24.

Zhang, W., Yang, F., Liu. A., Wang. R., Zhang, L., Shen, Y., Cao, J., \& Ling, H., (2013). Prevalence and genetic characterizations of Cryptosporidium spp. in pre-weaned and post-weaned piglets in Heilongjiang Province, China. PLoS One, 38(7), 122-124. 